\title{
Cryptozoology as a pseudoscience: beasts in transition
}

\author{
Elise Schembri
}

\author{
This study was conducted under the supervision of Professor Sofie Lachapelle, \\ Department of History, College of Arts \\ University of Guelph, Guelph, Ontario, Canada
}

\begin{abstract}
Cryptozoology, the pursuit of wildlife ignored or discounted by mainstream zoology, emerged as a separate discipline from zoology in 1955 with the publication of Bernard Heuvalmans' book On the Track of Unknown Animals. Although it is typically associated with pseudoscience, many of the discipline's advocates assert that cryptozoology should be recognized as a legitimate science. This has proven difficult because of the nature of the discipline and its inability to provide falsifiable evidence. This paper examines crytozoology's dichotomous separation from zoology; its search for hard evidence to support the existence of obscure creatures including hominids, sea serpents and lake monsters; and its efforts to document in a clear and objective way the existence of such creatures so as to distance itself from paracryptozoology as well as both the media and public's distorted understanding of the field. This paper argues that by its nature cryptozoology is bound to remain, at worst, a pseudoscience and, at best, a transitional field of research. The example of the discovery of creatures like the giant squid, which left the realm of mythology and became a recognised species of zoology in 2004, provides evidence of both the promises and the inherent problems of the field of cryptozoology.
\end{abstract}

$\mathrm{T}$ here are a number of disciplines considered to lie outside mainstream science whose practitioners seek professional respect and scientific recognition. These disciplines are often referred to as pseudoscience; and while some are irrefutably so, there are still gray areas where the separation between pseudo and mainstream or 'true' science becomes difficult to decipher. One discipline residing in this gray area is cryptozoology. Cryptozoology is the pursuit of wildlife ignored or discounted by mainstream zoology [1]. These creatures (defined as cryptids), while believed by most to be unlikely to exist, are by no means scientifically impossible. The work of cryptozoologists consists of recording sightings and obtaining proof of their existence in the various environments in which they are assumed to exist [2]. These investigations range from the hunt for obscure hominids (such as big foot and the yeti) or sea serpents and lake monsters (like Nessie and Champ), to the collection of evidence on the possible existence of yet unknown species in some of the still vastly unexplored regions of the world. This paper will attempt to place cryptozoology within its contemporary context by focusing on the factors that have prevented it from attaining scientific recognition and have subsequently confined it to its current state as a pseudoscience. By profiling several cryptids, as well as some species formerly considered cryptids, the difficulties experienced by cryptozoologists to dissociate themselves from the pseudoscience label will become apparent. The need to distance cryptozoology from folk tales will also be illustrated through the de-mystification of the extraordinary animal qualities, thought to be associated with cryptids, by explaining them in rational terms [3].

\section{CRYPTOZOOLOGY AS A DISCIPLINE}

Tales of mythological and wondrous creatures have always held a fascination for humans; and legends and stories of similar fantastic beings can be found in cultures across the world. Although there is certainly a long tradition of pursuing the prospective existence of undocumented creatures, the field of cryptozoology formally separated from zoology and came into its own in the second half of the twentieth century. The split was fuelled by the work of Bernard Heuvelmans, a French scientist with a $\mathrm{PhD}$ in zoology, who published his book On the track of Unknown Animals in 1955. Often presented as the 'father' of cryptozoology, Heuvelmans formed the International Society of Cryptozoology in 1982. The society was intended to be a scholarly centre for documenting and evaluating evidence for unverified animals. It had its own journal, Cryptozoology, which ran from 1982 to 1996 [1]. Its goals were to search for the possible existence of known animals in areas where they were currently believed not to exist, to discover animals presumed to have gone extinct in the distant, even, prehistoric past, and to explore the possibility of creatures whose existence is currently based solely on fragmentary evidence [2].

If they indeed exist, cryptids may now, like many other species on the planet, find themselves in an increasingly vulnerable position as pollution, deforestation and simple 
human negligence propels our generation towards a state of environmental crisis. There is consequently a sense of urgency among some cryptozoologists who believe that cryptids have remained unknown in large part because they inhabit unfamiliar and relatively inaccessible areas of the world, areas that are now being destroyed to meet the demands of an ever-expanding population [1]. Similar to many entomologists, who are still in pursuit of the vast quantity of insect species yet to be formally described, cryptozoologists have begun to play a new role as promoters of environmental values against the decimation of species and the destruction of their natural habitat [3]. Beyond all of this, cryptozoology often appeals to individuals looking for mystery, mysticism and even danger in a world now perceived as fully charted and over-explored. It can also appeal to those looking to articulate resentment of and defiance against a scientific community perceived as monopolising the pool of culturally acceptable beliefs [3]. There is no doubt that cryptozoology has its followers but the views held by the general public and the consensus of the overall scientific community lean far more towards ridicule and the rejection of this discipline as a legitimate science.

\section{Cryptozoology as a Pseudoscience}

Science has been characterized as that which uses a scientific method to validate testable claims and possesses characteristics such as empirical content, refutability, and the ability to form a consensus; characteristics that are traditionally not associated with pseudoscience [4]. A pseudoscience has been defined as a field that tries to appropriate the prestige of science and copies its outward trappings and protocols but essentially falls short of meeting the accepted standards of the practice of science [4]. It has been proposed that there are several contributing factors that keep cryptozoology from being recognized as a science. The first of these factors is isolation: cryptozoology exists outside of all contemporary types of science like biology, chemistry, and physics; although cryptozoology does function under the main principles of these disciplines, it also exists outside of them because its own specific principles have been rejected. Cryptozoology also lies outside mainstream science because it lacks falsifiability in its never-ending search for elusive creatures. Furthermore, cryptozoology is not cumulative or self-corrective. It is stagnant, with little evidence of progress, leaving it detached from mainstream science because of its inability to grow and accumulate knowledge [5]. Using these factors, however, a case can be made to legitimize at least some parts of cryptozoology, but there seems to be a strong aversion to even mentioning pseudoscience in the scientific community, almost as if it were taboo, and the association with pseudoscience subsequently puts cryptozoology at an inherent disadvantage for ever being seriously considered [3]. 'The deviant researchers are prevented from having impact on the mainstream scientific process, yet because of their commitment to the ideology of science, they nonetheless keep on trying to make such an impact. This tends to stabilize the process' [8a]. To try to circumvent this problem, it has been suggested that both science and pseudoscience are cognitive fields in their own right, whether genuine or fake, through their attempt to gain, diffuse and utilize knowledge of some kind. As such, cryptozoology - a pseudoscience - can be lumped together with religion and politics while science is conversely associated with research fields, including the humanities, mathematics and technology [4]. But, even attaining the same type of respect as religion and politics would be a huge feat for cryptozoology. Sociologist James McClenon makes a case for this type of deviant science based on scientist's communal desire to avoid affiliation and association with what are understood to be non-scientific groups [6]. He asserts that since scientific etiquette has to bypass qualified peer approval, boundaries and the labelling of certain behaviour inevitably emerge. McClenon continues by stating that these methods of demarcation are required for the sustainability of any type of long lasting community, especially an academic one [7].

\section{THE CRYPTIDS}

A large part of the problem facing cryptozoology in its quest for scientific legitimacy is that, for most scientists, cryptozoology is mostly associated with the search for two particular categories of species: obscure hominids like Sasquatch, and lake monsters like Nessie. The name Sasquatch comes from the 1920s Native Coast-Salish name meaning a large, hair covered, man-like creature. Although Sasquatch is one of the most well known names, the creature has over 200 additional names among Native American tribes alone [8]. Sasquatch is assumed to be nocturnal, and sightings have been claimed all over the world with minor variations between the legends. Similarly described creatures have been sighted in Quebec, the North West Territories, the Yukon, the Idaho Rockies, Washington and Oregon; and in these areas alone there have been over 3000 recorded sightings [8]. These sightings come from everyone: from hunters, to police officers, to teachers. For many cryptozoologists, the fact that these professionals very possibly have more to lose (reputation and credibility) than they do to gain from reporting a sight like this has given credence to their testimonies [8]. However, even Heavelmans acknowledges that 'the frailty of human testimony must be seriously considered [as] the witness may be honest but mistaken' [9a].

Cryptozoologists have sustained numerous attacks in their belief in the existence of a Sasquatch-like creature based on a substantial lack of evidence. To this, they have answered that lack of evidence does not necessarily mean lack of existence. For example, the absence of remains could be attributed to other inhabitants of the forest: it only takes a few days for ravens and bears to obliterate remains, mice and porcupines tend to make short work of bones, and phosphorus and calcium only lasts a few months [8]. It is therefore understandable that bones are not found for species 
with such a small population. Cryptozoologists have also argued that the forest canopy could act as a shield from infrared aerial searches. If the creatures dwell so deeply that they are veiled by this canopy, it could account for their ability to remain undetected [1]. It has also been hypothesized that Sasquatch may be a migratory ancestor of a giant Asian hominid named Gigantopithicus, the largest living hominid in recorded fossil history. This hominid lived 7.5 million years ago and was estimated to have survived until 0.5 million years ago; however its bell-shaped survival curve could easily fall into our present time, suggesting that there may be some ancestors still in existence. The difficulty of hoaxing the larger than human tracks because of the dermal bridges present on the toes, as well as the discovery of long hairs which could not be typed to any North American mammal have also been used to argue for the possible existence of an unknown hominid [8]. Of course, none of these arguments prove the existence of a Sasquatchlike animal, but, for cryptozoologists, they do at least provide sufficient evidence for the search of such creatures to be accepted, or at least tolerated, by mainstream science.

Another group of elusive creatures fighting for scientific relevance are Lake Monsters, specifically the Loch Ness Monster and Champ of Lake Champlain. Lake monsters have been described from Scotland to Argentina and from Canada to the Congo. Legends of sea and lake monsters can be traced back to sailor's tales of the Kraken, which was a giant squid-like creature, and similarly back to Native American legends [2]. Sightings of the Loch Ness monster can be traced back to over 1000 years and although lake monsters tend to be associated with wild and unsubstantiated claims, evidence still persists for the possibility of their existence. In 1933 there were over 20 reports of Nessie over just a 6 month period. In 2003, echolocation surveillance was performed in Lake Champlain and discovered strange noises that most likely belonged to some sort of large creature making sounds similar to those of a whale but definitely of a different and unidentifiable species [10]. It has been hypothesized that what we consider to be lake monsters are simply descendants of dinosaurs like the plesiosaur (an aquatic reptile thought to have survived 160 million years ago until about 60 million years ago) [1]. This understanding is evidence of how the sea monster model is morphing into a more 'scientific' model based on a prehistoric aquatic creature.

Despite these more sophisticated methods of understanding sea and lake monsters, Nickell and Radford have suggested that the very popularity of the 'myths' would seem to disprove their existence [10]. For example if Nessie exists, the creature has been able to escape decades of extensive sonar searches, the discovery of any floating or beached corpses, and the production of any type of irrefutable pictures or samples to prove its existence. Sightings have been credited to otters, eels, logs, beavers, and very often, lake sturgeons. The species would need to maintain a herd size of at least 12 individuals for breeding purposes, and yet these individuals have somehow managed to, supposedly, exist without leaving a shred of hard evidence behind [11]. Similar to sightings of Sasquatch, reports of lake and sea monsters almost invariably correspond with the public's interest in the creatures, suggesting an obvious social and cultural engine fuelling the reports.

\section{LEGITIMIZING THE HUNT}

Despite all the differing attitudes and understandings preventing cryptozoology from reaching its possible scientific potential, cryptozoologists continue to pursue their elusive cryptids, even in the face of ridicule. In the 1968 publication of his book In the Wake of Sea Serpents Bernard Heuvemans dedicated it in part to these individuals "who in perfectly good faith have bravely reported facts not easy to believe.' There are many reasons used by cryptozoologists to justify continuing their research, some of which are based on the discoveries of new areas in the world and species traditionally thought to have been extinct in the distant or recent past. For example, as recently as November of 2001, scientists in Ecuador discovered a 123500 acre 'virgin' forest that had, as far as researchers could tell, never before been seen by humans [1]. In February of 2003, satellite photos revealed 1000 previously unknown islands in the Indonesian archipelago, and in June of that same year the research ship Tangaroa found 400 new marine species during a mere two week survey of New Zealand's coastline [1]. In addition to these discoveries in December of 2005, scientists found a jungle 'lost world' in Papua New Guinea and discovered 40 new animal species, including a bird which had only been seen once before in 1897 [1]. With humanity's constant quest for the unknown we are often left feeling that we have solved all the mysteries of the world, but with such recent and such large discoveries still seemingly widespread and possible, how can it be claimed as an absolute truth that cryptid species are an impossibility? Discoveries of new areas, and the species within them, keep cryptozoology alive, and render cryptozoologists ever hopeful and resilient in their hunt for the mysterious.

For even further justification of cryptozoology, one needs only to look into recent history. There is extensive documentation and ancient mythology involving large and fantastic species, which used to be considered cryptids, whose existences are now considered common knowledge. For example, the Lowland Gorilla was discovered only in 1847, the Vu Quong Ox was discovered in 1992, and the Leaf Muntjac Monkey was discovered as recently as 1997 [1]. In 2005 Frederick Crassle, director of Rutgers University's institute of marine and coastal sciences, estimated that the world's oceans still contain about ten million unknown species [1]. However, despite all of these emergences of new species into scientific knowledge none have influenced the pursuit of cryptozoologists to the extent that the discoveries of the coelacanth and the giant squid have. It can be argued that these two species revolutionized 
the discipline and presented a new lens through which to understand the pursuit of the unknown as a legitimate use of resources.

The coelacanth is a fish that grows to about 5 feet long, whose fins resemble legs in appearance and function, and who resides approximately 700 metres below the ocean's surface. In 1938, the first living coelacanth ever recorded was caught by a fisherman. This catch holds tremendous importance for cryptozoologists because fossil records have placed the fish as far back as 410 million years ago, and it had been thought to have been extinct for at least 60 million years [2]. For this reason, and the fact that the fish has remained virtually unchanged from its prehistoric form, it has been referred to as a 'living fossil' and has understandably attracted a great deal of attention from zoologists and cryptozoologists alike [2].

The other great creature whose discovery gave credence to the importance of cryptozoology is the giant squid. The first footage ever taken of the giant squid, Architeuthis, estimated it to be about 43 feet long, and was taken by researchers from the National Museum of Japan in 2004 [12]. Before this footage, the giant squid had been primarily the focus of cryptozoologists and many respected zoologists had doubted its existence. However, with its discovery, zoologists and cryptozoologists alike have found themselves pushed towards new questions and possibilities pertaining to the boundaries of scientific thinking. Unfortunately for cryptozoologists, the hard confirmation of the existence of a mythical creature they had been searching for did not lead to clear progress. The giant squid, now a confirmed animal, left the world of myth and cryptoptozoology to become a part of zoology. It is the nature of the discipline that once the cryptids are no longer in the transitory state between myth and reality, they no longer belong to the cryptozoologists.

\section{The Public's Perception}

For certain media sources, myths and rumors of cryptids are always sensational topics to cover. Their treatment of crytozoology and its supposed creatures inevitably fuels stereotypes that can be hard to overcome. Despite clear evidence of the existence of certain previously unknown species, cryptozoologists have a hard time escaping the sensational claims of Bigfoot sightings that frequently cover the front pages of certain tabloids. In fact, Alley states that the Bigfoot of the tabloids is so far removed from the nature of a real primate that it bears little resemblance to the creatures of the reports [8]. We need not look far to see how the public's misconception of these creatures has been fuelled by popular culture. Movies like Harry and the Hendersons, the story of a loveable and funny Bigfoot that goes to live in a city family's home and gets into all kinds of mischief is a perfect example of this, as is the tourism organized around claims of a Loch Ness monster, from the market for souvenirs to the submarine rides into the supposed home of this fantastical creature. 'What used to be healthy scepticism is now only lazy ridicule,' states Alley [8].
Through tabloids and tourism, the public has learned to treat the hunt of cryptids as a joke, even though their existence is not always impossible [2].

Alley reported that as of 2003 there were only about twelve $\mathrm{PhD}$ holders willing to openly associate themselves with cryptozoology and subsequently defend whatever is left of the reputable nature of the discipline and its quest for new knowledge and tangible links to the past. Excluding those twelve individuals, if there are any other $\mathrm{PhD}$ holders, who are not legitimate sceptics, it can be assumed they fear supporting cryptozoology because of the consequences it may elicit on their own research or career. This could include a lack of respect from their peers, having their objective opinions and judgements as researchers brought into question, and having an overall, laughable attitude taken towards them within the scientific community. For many, these risks are too great. Cryptozoology then appears to enter a vicious cycle fuelled by public opinion in which no grants are given for funding because there is no hard evidence proving the existence of cryptids, but it is possible that evidence does not exist in part because there is no research as a result of no grants being given [8]? In 2003 Canadian Wildlife Biologist Dr. John Bindernagel suggested that what the public and the scientific community both need is a change of perspective [1]. A mere legend does not jump easily from one culture to another. So the questions we should be asking are: if such creatures exist, what do they eat?, when do they sleep?, and perhaps how do they survive the winters?

\section{PARACRYPTOZOOLOGY}

Another element preventing cryptozoology from reaching scientific legitimacy is its association with paracryptozoology. Paracryptozoology is concerned with the most paranormal of cryptozoology reports including dragons, unicorns, satyrs, centaurs, and merbeings. It may also occasionally include paranormal elements such as creatures appearing or disappearing, and in the past it has been linked with UFOs [2]. Ironically, cryptozoologists often attempt to dissociate themselves from paracryptozoology in the same way that zoologists attempt to dissociate themselves from cryptozoology. Cryptozoologists strongly dismiss the claims of paracryptozoologists and take pains to separate themselves from their research, not least because of its reference to the existence of parallel universes and alternate realities. Much more extreme than cryptozoologists, paracryptozoologists push their search into fantasy, characterizing lake monsters like Nessie as dragons and attributing the existence of other cryptids to demonic forces providing a counterbalance to the forces of good in the world [2]. Needless to say, paracryptozoology is built on a far different foundation than cryptozoology and diverges drastically from the scientific base of research on which cryptozoologists pride themselves.

Two creatures in particular are strongly associated with paracryptozoology and serve to illustrate the differences between paracryptozoology and cryptozoology as 
disciplines: the unicorn and the merbeing. Unicorns, literally translating to 'long horn' in Latin, have been reported throughout the world since ancient times and we can find them described in ancient Greek texts on natural history, perhaps suggesting that they were seen as real creatures of flesh-and-blood at the time [1]. These beasts were described as horses with a goat-like beard, a tail resembling that of a lion, cloven hooves like those of a cow or deer, and of course a horn [13]. Unicorns may not seem to be overly mysterious upon first literary, or otherwise, encounter, but the magical part of them is thought to be the healing power of their blood and/or horn. Paracryptozoologists are fascinated by unicorns because stories often describe them as part of an alternate reality from where they make chosen appearances in our own reality. Although unicorns are more closely tied to paracryptozoology, explanations for confirmed sightings and capture are fairly easy to explain compared to other cryptid chased by cryptozoologists. For example, the African horned Oryx has two very long horns, but in the summer months these horns will often become brittle with the heat which can cause them to snap off, leaving them with one long curved horn [1]. Similar explanations can be applied to the apparent capture and 'undeniable' sightings of unicorns, which can be understood as a human plea for mystery and magic. This illustrates the more rational and scientifically grounded understanding of the creatures that is conveyed through cryptozoology.

Another creature that fascinates paracryptozoologists is the merbeing [13]. The work of early zoologists and historians was filled with tales of mermaids, and there are legends of them found in every area in the world with access to the sea, some of which persist up until the present day [14]. The International Society of Cryptozoology went to New Guinea in pursuit of the reports of merbeings there, known to the natives as ' $\mathrm{Vi}$ ', but they had no success. These creatures were described by the natives as air breathing mammals with the trunk, genitalia, arms and head of a human being and a legless lower trunk terminating in lateral fins or flippers [11]. Merbeings are often associated with cryptozoology, but the ones that are studied by paracryptozoologists are thought to be super intelligent aliens who may have been abandoned on our planet. These particular merbeings are said to have a body that they created to observe and interact with humans, while still being able to remain hidden [1]. It has also been suggested that sightings of merbeings were simply seals, or hallucinations of sexstarved sailors out on long voyages at sea [14].

There is of course some overlap between cryptozoology and paracryptozoology, as, at times, many cryptozoologists have found themselves pursuing creatures like unicorns and merbeings for which there appears to be no scientific justification. However, under closer inspection it becomes obvious that the more obscure and skewed the claims of existence and origin become, the more cryptozoologists have a tendency to distance themselves from the search for a particular species. It is the difference in the reason for studying these creatures and the understanding of them in a more grounded and scientific context that really distinguishes cryptozoology from paracryptozoology. Often the wild claims preached by paracryptozoologists have little or nothing to do with the pure pursuit of unknown species.

\section{CONCLUSION}

In conclusion it would appear that cryptozoology is a victim of several circumstances that prevent it from obtaining the respect and the recognition of the larger scientific community. Media depictions of cryptids and cryptozoologists have morphed them both into a laughable matter in the public realm. This has resultantly made cryptozoology a private shame of some scientists who fear ridicule and a loss of credibility should they voice their interest in the field. Moreover, the lack of genuine physical and photographic evidence of cryptids constrain cryptozoologists to launch expeditions on the sole basis of so-called reliable eye-witness accounts leaving them at the mercy of the undeniable constructive nature of perception and memory [11]. Furthermore, the discipline of paracryptozoology binds the discipline further by associating it with wild claims and unsubstantiated evidence which causes the public to further question the intent and rigour of cryptozoology. Finally, any result of the field that might be used to justify its use and interest for science is rapidly transferred to zoology, leaving cryptozoology once again a field of supposition.

It has been argued by that it is the fear of science students accepting certain claims as scientific facts that has precluded what is considered pseudoscience from entering mainstream science, even though it is an important aspect of scientific education; this essentially refers to a common fear held among the scientific community that if certain pseudosciences are given scientific recognition without substantial evidence it may once again blur the line between myth and reality [6]. It seems a dangerous assumption, however, that myths and legends associated with the cryptids, which arose in parallel to one another all over the world, did so coincidentally. Perhaps, they should not be discounted so easily. It may be beneficial to legitimize cryptozoology as a science in an attempt to simplify the life of the researchers pursuing this knowledge through attempting to find hard evidence. 'Cryptoscientific claims are (at least in theory) relatively easy to validate but difficult to disprove' as the capture of a cryptid proves its existence but the failure to capture one does not disprove it [7b]. For this reason access to resources and funding may have a profound impact on the discipline.

Creatures like the giant squid were once only pursued by cryptozoologists and now their existence is common knowledge, so it is entirely possible that other cryptids are still dwelling in limbo between fantasy and scientific recognition to be discovered by cryptozoologists and recognised by the scientific community. The squid was discovered, not by cryptozoologists, but by scientists and as 
such the finding was validated within the scientific community; this is what the pursuit of most cryptids is lacking. Believers and hunters of these cryptids have persisted throughout time, despite the sceptics, and it is possible that our romantic belief in monsters needs no evidence to keep some individuals hunting for mysteries in the world. But is it entirely impossible that these creatures are simply too intelligent to be found by mankind; that they have understood the way in which we have destroyed the rest of the planet as a direct threat to their own existence or have simply been trying to maintain their species by doing everything in their power to stay away from us? Discovery would undoubtedly bring new knowledge and new questions, but also new fear, new destruction, and new trophies from a new species to hunt. The pursuit of these cryptids can at least be considered more than a laughable fantasy in cryptozoology's plight for scientific recognition. Until then, by its nature, cryptozoology is bound to remain, at worst, a pseudo-science and, at best, a transitional field of research between mythology and zoology.

\section{REFERENCES}

1. Newton, M. (2009). Hidden Animals. Greenwood Press. Santa Barbara: California.

2. Williams., W. (2000). Encyclopaedia of Pseudoscience. Book Builders Incorporate, New York: NY.

3. Dendle, P. (2006). Cryptozoology in the Medieval and Modern Worlds. Folklore, 117:2, 190-206.
4. Bunge, M. (1984) What is Pseudoscience. The Skeptical Inquirer, 9, 36-42.

5. Beyerstein, B. (1996). Distinguishing Science from Pseudoscience. Department of Psychology: Fraser University. Victoria: B.C.

6. 6. Martin, M. (1994). Pseudoscience, the Paranormal, and Science Education. Science and Education, 3, 357-321.

7. Mclendon, J. (1984). Deviant Science- The Case of Parapsychology. Press USA. University of Pennsylvania. a:221, b:36.

8. Alley, R. (2003). Raincoast Sasquatch- The Bigfoot/Sasquatch Records of Southeast Alaska, Coastal British Columbia \& Northwest Washington from Puget Sound to Yakutat. Hancock House Publishers Ltd. Surrey: B.C.

9. Heuvelmans, B. (1958). In the Wake of Sea Serpents. Mill and Wong, USA. a:29.

10. Nickell, and Radford. (2006). Lake Monster Mysteries. The University Press of Kentucky, Kentucky.

11. Hines, T. (1988) Pseudoscience and the Paranormal. Prometheus Books, Buffalo: NY.

12. Kubodera T., and Mori, K. (2005). First-ever observations of a large giant squid in the wild. Proceedings of the Royal Society, 272, 2583-2586.

13. Barber, R., and Riches, A. (1971). A Dictionary of Fabulous Beasts. Macmillan London Ltd., Toronto.

14. Hutchins, J. (1968). Discovering Mermaids and Sea Monsters. Shire Publications, Tring: Herts. 